\title{
О МЕТОДОЛОГИИ ПРИНЯТИЯ РЕШЕНИЙ ПО ОБЕСПЕЧЕНИЮ БЕЗОПАСНОСТИ ВАЖНЫХ ЭКОНОМИЧЕСКИХ ОБЪЕКТОВ В УСЛОВИЯХ УГРОЗЫ ДИВЕРСИОННО-ТЕРРОРИСТИЧЕСКОГО ВОЗДЕЙСТВИЯ
}

\author{
А.Г. МИХАЙЛОВ \\ доктор военных наук, профессор \\ кафедры Менеджмента таможенного \\ и страхового сервиса СПб ГУСЭ
}

\begin{abstract}
Аннотация:
В данной статье рассмотрен определённый методологический подход к обеспечению безопасности важных экономических объектов в условиях угрозы диверсионно-террористического воздействия раскрытый на примере проектирования эффективной системы их охраны, обеспечивающей определенный уровень непосредственной противодиверсионной защищенности объекта адекватный уровню угрозы.

Отдельное внимание в статье уделяется вопросу научной организации системы охраны, которая направлена на обоснование рационального варианта решения по ее составу, построению (эшелонированию) и способам применения сил и средств.
\end{abstract}

\section{ВВЕДЕНИЕ}

В современных условиях, характеризующихся общей нестабильностью политической обстановки в мире и повсеместным всплеском террористической активности, в том числе и в России, резко возрастает значение научно обоснованной организации защиты подведомственных объектов от диверсионнотеррористического воздействия различных экстремистских, террористических и просто уголовных (бандитских) групп. Данное требование в полной мере распространяется и на многочисленные экономические объекты (энергетические, производственные, транспортные складские и пр.), которым в наибольшей степени угрожают экстремисты. В настоящей статье раскрываются проблемные вопросы обеспечения безопасности функционирования важных экономических объектов в условиях эскалации угрозы диверсионно-террористического воздействия (ДТВ).

Обеспечить эффективную защиту объектов в условиях угрозы диверсионно-террористического воздействия противника возможно путем создания единой системы противодиверсионной защиты (ПДЗ) важных зон, районов и объектов. Создание такой системы предполагает привлечение к решению задач ПДЗ всех расположенных (дислоцированных) в этих зонах (районах) сил и средств различных силовых структур государства, способных по своему предназначению, возможностям и уровню подготовки эффективно вести борьбу с 
диверсионно-террористическими и прочими враждебными формированиями. Созданная по зональному (зонально-объектовому) принципу, такая группировка сил и средств, рассматриваемая в работе как система, призвана обеспечить требуемый (достаточный) уровень противодиверсионной (антитеррористической) защищенности расположенных в зоне объектов за счет умелого (искусного) их применения, централизованного и эффективного управления. Для обеспечения командиров и штабов соответствующими штабными методиками и другими средствами, позволяющими обоснованно принимать эффективные решения на ПДЗ зон, районов и объектов, требуется разработка специально ориентированного научно-методического аппарата, отсутствующего в настоящее время в органах управления (войсках).

В связи с этим одним из важнейших проблемных вопросов, требующих скорейшего решения, становится вопрос разработки и внедрение в практику органов управления методологии принятия научно обоснованных решений по обеспечению безопасности объектов в условиях угрозы ДТВ. Методология предполагает описание структуры и логической организации процесса принятия таких решений и включает комплекс специальных методов, моделей и методик, обеспечивающих обоснование структуры, состава, построения (эшелонирования) и способов применения сил и средств, составляющих основу системы ПДЗ определенных зон, районов и объектов.

В настоящей статье рассматривается лишь часть разработанной методологии, описывающей процесс создания (проектирования) небольшого, но очень важного структурного элемента общей системы ПДЗ зоны (района) - системы охраны отдельных важных объектов, призванной обеспечить непосредственную (объектовую) противодиверсионную защищенность охраняемого объекта адекватную степени угрозы ДТВ.

Указанная выше проблема, была решена автором еще в 2005 году [1]. Тем не менее, полученные в ходе исследования результаты, то есть определенные выводы, предложения и рекомендации в силу целого ряда причин, в большей части так до сих пор и не реализованы. Это вызывает необходимость переосмысления ряда ранее разработанных теоретических положений и приведения их в соответствие с новыми условиями, характеризующимися, прежде всего, значительным сокращением военной мощи государства и численности списочного состава формирований силовых структур.

При этом следует отметить, что вопросы защиты от угрозы диверсионнотеррористического воздействия, как правило, не входят в перечень информации, публикуемой в научных издениях открытого доступа, поэтому основными теоретическими трудами по теме исследования являются работы Емельянова В.П., Гайдука Э.Г., Даниленко Н.Н., касающиеся различных аспектов проблемы террористического акта.

В связи с этим, цель данной публикации ознакомить всех заинтересованных лиц с общими результатами ранее проведенного исследования и, в частности, с вопросами методологии принятия обоснованных решений по обеспечению безопасности важных экономических объектов в условиях угрозы дивер- 
сионно-террористического воздействия. Для иллюстрации применения методологии в статье рассмотрен частный случай обеспечения безопасности - на примере обеспечения непосредственной противодиверсионной защищенности объекта путем создания (проектирования) эффективной системы его охраны.

Структура статьи включает введение, два подраздела, заключение и список литературы. Данная структура позволяет получить представление о разработанном методологическом подходе к обеспечению безопасности важных экономических объектов в рассматриваемых условиях обстановки, а также о содержании и последовательности действий разработчиков-аналитиков по научной и частично практической организации системы охраны. В тексте статьи размещены два рисунка, иллюстрирующие представленный теоретический материал.

Методологической основой проведенного исследования является системный подход. В качестве теоретической базы использовались известные методы формальной логики, теории исследования операций, теории организации, системного анализа, математического моделирования, оперативно-тактических расчетов, историко-аналитический метод и целый ряд других общенаучных и специальных методов исследования [2-7], в том числе и специально разработанных автором для решения рассматриваемой проблемы [1].

\section{РЕЗУЛЬТАТЫ И ИХ ОБСУЖДЕНИЕ}

Обоснование методологического подхода к обеспечению безопасности объектов

Действия по нейтрализации угрозы диверсионно-террористического воздействия (ДТВ) могут проводиться в рамках мероприятий противодиверсионной (антитеррористической) борьбы (ПДБ) и противодиверсионной (антитеррористической) защиты (ПДЗ) определенных территорий (зон, районов, рубежей) и объектов.

Под «противодиверсионной (антитеррористической) защитой зон, районов, рубежей и объектов» в работе понимаются заранее подготавливаемые и своевременно проводимые мероприятия (агентурные, оперативно-розыскные, разведывательно-поисковые, режимные, охранные, инженерные, инженернотехнические, обеспечивающие и другие ) и действия (боевые, специальные, разведывательные, режимные, охранные и другие), направленные на обеспечение безопасной жизнедеятельности населения, работы государственных, экономических и иных важных объектов, повышение их защищенности, живучести и устойчивости функционирования в условиях эскалации угрозы диверсионнотеррористического воздействия.

В данном контексте понятие «защита» выступает как совокупность всех мер и действий, предпринимаемых государством для ограждения (защиты, охраны и обороны) своих граждан, природных ресурсов и разнообразных объектов от возможных террористических угроз.

Генеральной целью всех этих действий является обеспечение безопасности функционирования элементов экономических (энергетических, производствен- 
ных, транспортных и др.), социальных и других систем государства, расположенных в границах зон (районов, рубежей) определенных для проведения мероприятий ПДБ и ПДЗ.

При этом под «безопасностью» в работе понимается достижение такого состояния защищенности охраняемых объектов, при котором им не угрожает опасность негативного (поражающего) воздействия определенных внешних и внутренних факторов.

Решение проблемы обеспечения безопасности функционирования объектов в условиях угрозы диверсионно-террористического (криминального) воздействия требует применения разнообразного научного инструментария - концепций, принципов, методов, моделей и методик из арсенала многих отраслей науки (логики, математики, психологии, социологии и др.). Разработанный методологический подход главным образом основывается па применении законов и принципов формальной логики, методов системного анализа и математического моделирования. При этом необходимо отметить приоритет логического мышления. Какие бы методы и математические модели не применялись для доказательства правильности решения исследуемой проблемы главное, чтобы мышление исследователя-аналитика было определённым, последовательным, непротиворечивым и обоснованным (доказательным) - одним словом, логическим.

Таким образом, в основе предлагаемого методологического подхода лежит строгое соблюдение основных законов формальной логики (прежде всего законов тождества, противоречия, исключённого третьего и достаточного основания), позволяющих получить истинное знание об исследуемом объекте. Неоспоримым критерием истинности в любом деле служит практика. Поэтому для получения таких знаний требуется не только следование формально-логической правильности рассуждений, но и постоянное обращение к практике, к сверке с ней каждого логически самостоятельного этапа исследования. Без этого невозможно добиться правильности теоретических обобщений, сделать точные, обоснованные выводы и показать их практическую значимость.

С учетом законов и правил формальной логики сформирован определенный методологический подход к исследованию проблемы обеспечения безопасности объектов, включающий последовательное обоснование структуры, логической организации, методов и средств, то есть определенных моделей и методик, обеспечивающих обоснование решений на создание эффективной системы охраны важных экономических объектов. Помимо этого на методологическом и концептуальном уровнях разработаны соответствующие концепции и принципы эффективности охраны по обеспечению безопасности важных объектов, развит и адаптирован к рассматриваемой проблематике соответствующий понятийный аппарат.

Логическая организация, рассматриваемая как основа методологии, включает: 
- анализ внешних и внутренних условий (факторов), влияющих на эффективность создаваемой системы охраны объекта (проведение факторнопараметрического анализа);

- последовательное обоснование целей, задач и требований к системе охраны, адекватных внешним и внутренним условиям (факторам);

- определение целесообразных характеристик системы охраны объекта и разработка соответствующих моделей ее построения и использования;

- анализ противодиверсионной защищенности объекта (уязвимости системы охраны) и выявление по результатам анализа «уязвимых мест» системы, требующих структурных, организационно-технических, информационных и иных усовершенствований (например, усиления, эшелонирования, дублирования, резервирования, модернизации, унификации и др.);

- проектирование усовершенствований системы с последующей оценкой (проверкой) эффективности планируемых мероприятий, продолжающихся до получения удовлетворительных (требуемых) результатов выраженных численными значениями выбранных критериев (показателей) эффективности.

Реализация предложенного методологического подхода осуществляется на базе специально ориентированного научно-методического аппарата, включающего комплекс общенаучных и специальных методов исследования, а также специально разработанных моделей и методик, применяемых в соответствии с разработанной структурой и логической организацией данного исследования.

К общенаучным методам относятся такие методы как наблюдение, эксперимент, анализ, синтез, моделирование, систематизация, классификация, а также методы логики, математики и других базовых дисциплин.

К специфическим методам относятся методы системного анализа, методы исследования операций, методы математического моделирования и другие [27], а также методы, специально разработанные для реализации в данной области [1]. Совокупность всех перечисленных выше методов, применяемых в определенной логической последовательности, составляет основу методологической базы исследования.

Другую часть методологической базы обоснования решений по обеспечению безопасности функционирования экономических объектов составляют специально разработанные концепции и принципы*, в соответствии с которыми проводятся все последующие логические умозаключения и аналитические действия (операции), в том числе с использованием методов структурнологического и математического моделирования.

(*- Принципы эффективности охраны по обеспечению безопасности важных экономических объектов в данной статье не рассматриваются).

Первой концепцией, то есть главной, ведущей идеей, на базе которой проводится моделирование (прогнозирование) развития обстановки и вырабатываются соответствующие организационные решения является концепция «разумных действий сторон».

Данная концепция предполагает взаимную рационализацию действий противоборствующих сторон, то есть с одной стороны - сил охраны объекта, а с 
другой - террористов, в мере разумного и целенаправленного использования ими имеющихся возможностей и ресурсов. Иными словами, применение концепции предполагает, что террористы применяют наиболее целесообразные в рассматриваемых условиях способы и приёмы ДТВ, а силы охраны стремятся к рациональному построению и применению имеющихся средств, для нейтрализации диверсионно-террористической угрозы с минимальными потерями и затратами ресурсов (в том числе, временных).

Необходимо уточнить, что в этом случае под «рационализацией действий» понимается достижение максимально возможной в рассматриваемых условиях обстановки экономической и служебно-боевой эффективности использования имеющихся сил, средств и ресурсов.

Вторая концепция - концепция «гарантированного результата действий сторон». Она предполагает, что каждая из сторон будет стремиться получить решение своей проблемы гарантировано, то есть с учётом не только объективного и всестороннего анализа текущего состояния сил и средств и на основе их рационального применения, но и с учётом перспективы их изменения на расчётный период. Например, террористы, если решили, обязательно осуществят нападение на объект, дождавшись самых благоприятных для себя условий.

Третья концепция - концепция «критической альтернативы (крайнего пессимизма)». Она характеризует выбор сторонами такого варианта действий, который представляет для другой стороны наиболее неблагоприятный исход. Это означает, что из всех возможных способов каждая из сторон выберет с очень высокой вероятностью для реализации такой способ, который принесёт другой стороне наибольший ущерб и максимум в достижении конечной цели её действий.

Четвёртая концепция - концепция «дифференцированности (пропорциональности) защищённости объектов (элементов объектов) в соответствии с их важностью». Все объекты и их элементы невозможно и нецелесообразно защищать с одинаковой эффективностью. Силы и средства охраны должны быть сосредоточены в то время и на тех объектах (элементах объектов), которым в данный момент угрожает наибольшая опасность. Эта концепция определяет стратегию обеспечения безопасности объектов или их элементов в соответствии с их важностью и позволяет при наименьших затратах ресурсов добиться максимально возможной живучести и в целом безопасности их функционирования.

Таким образом, сформулированные концепции эффективности охраны по обеспечению безопасности (живучести) экономических объектов представляют собой существенную часть методологической базы решения рассматриваемой проблемы. С использованием их подготовленный аналитик может корректно создавать варианты исходной обстановки для моделирования хода и исхода противодействия сил охраны террористическим атакам и успешно обосновывать эффективную систему охраны, адекватную угрозе диверсионнотеррористического воздействия. 
Для более глубокого понимания сущности стоящей проблемы и корректной постановки, связанных с её решением задач, необходимо уточнить и расширить соответствующий понятийный аппарат, который, наряду с разработанными концепциями, составляет определенную часть методологической базы исследования. В процессе работы над развитием понятийного аппарата были уточнены такие понятия как защищённость, живучесть, устойчивость, безопасность, эффективность и ряд других, при этом все понятия и определения были максимально адаптированы к рассматриваемой проблематике.

Под «противодиверсионной защищённостью» объекта будем понимать его совокупную способность противодействовать и противостоять воздействию на него определённых формирований (групп) с использованием определённых средств поражения и способов диверсионно-террористического воздействия. При этом слова «противодействовать» и «противостоять» характеризуют соответственно активную и пассивную способность системы охраны объекта (сил и средств охраны) вступать во взаимодействие с внешними факторами.

Противоположенным по смыслу понятию «защищённость» является понятие «уязвимость».

Под «уязвимостью» объекта (системы охраны объекта) понимаем степень его возможного поражения (разрушения) при воздействии определёнными средствами, а также степень преодолеваемости защитных (охранных) рубежей при попытке их преодоления диверсантами.

Живучесть является более общим системным понятием по отношению к защищённости.

Под «живучестью» объекта будем понимать его совокупную способность сохранять и восстанавливать функциональные (боевые) возможности для выполнения задач по предназначению в условиях определённого диверсионнотеррористического воздействия на основе обеспечения определённой противодиверсионной защищённости и с учётом восстановления работоспособности (боеспособности).

Устойчивость является еще более широким (общим) системным понятием. Она связана с целым рядом других понятий, характеризующих способность персонала, оборудования и механизмов, зданий и сооружений сохранять свою работоспособность в условиях, отличающихся от нормальных. В связи с этим под «противодиверсионной устойчивостью» объекта будем понимать его совокупную способность сохранять определённые уровни работоспособности и выполнять функциональные задачи по предназначению в условиях определённого (прогнозируемого) диверсионно-террористического (криминального) воздействия.

Обеспечение защищённости и повышение живучести (устойчивости) объектов связано с проведением определённых охранных и защитных мероприятий. Целью их проведения является достижение «безопасности», то есть такого состояния защищённости объектов, при котором им не угрожает опасность поражающего воздействия со стороны противника. 
Bсе перечисленные выше понятия наиболее компактно и однозначно увязываются между собой при «оценке эффективности охраны», под которой будем понимать совокупную способность сил и средств охраны обеспечивать определённые уровни противодиверсионной защищённости, живучести и безопасности функционирования объектов в условиях ДТВ.

Необходимо различать понятия «оценка» и «оценивание».

Под «оцениваем эффективности» понимается нахождение качественно лучшего варианта решения и сравнение его с одним из возможных вариантов тем, который оценивается.

Как видно из определений, для прогнозирования (оценивания) живучести объекта необходимо сначала оценить степень его противодиверсионной защищённости (уязвимости). Затем, исходя из результатов оценки защищённости, спрогнозировать возможный состав, цели, задачи и способы действий диверсионно-террористических формирований (групп), а далее на основе известной защищённости (уязвимости) и прогнозируемого характера действий диверсантов, используя данные о составе и возможностях сил и средств охраны и персонала объекта, рассчитать уровни его гипотетической живучести и устойчивости.

Знание результатов такого прогноза поможет аналитику вскрыть все уязвимые участки в системе охраны объекта и предполагаемые последствия от их преодоления; наметить меры по устранению «уязвимых мест»; заранее спланировать адекватные и упреждающие действия сил охраны объекта и решить другие задачи, обеспечивающие сохранение работоспособности (боеспособности) оборудования и персонала. Данная логическая последовательность легла в основу предлагаемого методологического подхода обеспечения безопасности важных экономических объектов на основе прогнозирования уровней их противодиверсионной защищённости и живучести в условиях реализации угрозы ДТВ.

Целесообразность принятия данного подхода наглядно показана на рисунке 1. Из него видно, что для получения достоверных результатов при оценке уровней противодиверсионной защищённости (уязвимости), живучести и устойчивости объектов необходим комплексный, системный подход к оценке всех факторов, влияющих на их состояние. При этом игнорирование хотя бы одного из них ведёт к снижению точности вычислений, понижает достоверность результатов и, в конечном счёте, не позволяет обосновать адекватную систему охраны, необходимую для обеспечения безопасности функционирования объекта.

Важно подчеркнуть, что отраженные на рисунке 1 понятия, такие как «эффективность противодиверсионной защиты (охраны)», «защищённость (уязвимость)», «живучесть» и «устойчивость» работы объекта тесным образом взаимосвязаны. Все они обладают признаками системности, обобщённости и в значительной мере иерархически связаны между собой по признаку индукции и по логике вычисления соответствующих показателей, характеризующих количественно-качественную меру их измерения. 
Противодиверсионная устойчивость объекта достигается при условии, если обеспечена его живучесть. В свою очередь живучесть объекта в условиях диверсионно-террористического (криминального) воздействия обеспечивается в случаи, когда обеспечены определённые уровни его противодиверсионной защищённости (уязвимости) на основе эффективного применения сил и средств охраны. При достижении определённого уровня эффективности охраны обеспечивается безопасность функционирования объекта.

Таким образом, исследование по обеспечению безопасности экономических объектов необходимо проводить комплексно, оценивая множество факторов и показателей, что требует в качестве методологической основы его проведения выбрать системный подход, а основными методами исследования - методы системного анализа и исследования операций.

Научная организация системы охраны важных экономических объектов

Организация какого-либо процесса, в том числе и проектирования системы охраны, предполагает создание условий для эффективной реализации целей системы, бесперебойного и непрерывного ее функционирования в различных условиях обстановки.

Организовать - это значит: а) создать новую систему там, где ее ранее не было; б) улучшить состояние уже существующей системы (улучшить ее организационную форму) в соответствии с изменяющимися внутренними и внешними условиями; в) создать условия для эффективного функционирования системы.

Рассмотрим наиболее сложный вариант процедуры организации системы охраны - при ее первоначальном создании (вариант «а»). Можно выделить следующие основные этапы и элементы процесса научной организации системы охраны.

Подготовительный (информационно-аналитический) этап.

Этап включает проведение комплекса мероприятий по уяснению задачи, всесторонней подготовке необходимой (релевантной) исходной информации для последующего исследования, определению целей, задач и структуры исследования, разработке (выбору) соответствующего научно-методического аппарата и др.

Основными элементами процесса организации на этом этапе являются:

1. Сбор, обобщение, анализ и систематизация необходимой информации (данных).

2. Определение (четкое формулирование) назначения системы и диапазона условий ее функционирования.

3. Разработка основных требований к системе и ограничений, соответствующих выбранному диапазону условий ее функционирования.

4. Обоснование методологического подхода к процессу создания системы, то есть структуры, логической организации, методов и средств обоснования ее состава, способов построения, порядка функционирования и всестороннего обеспечения. 
5. Разработка (определение) основных методологических концепций и принципов создания и функционирования системы. При необходимости развитие (уточнение) соответствующего понятийного аппарата, обеспечивающего реализацию данных концепций (принципов).

6. Обоснование, выбор, а при необходимости и разработка новых методических средств (методов, моделей, методик), обеспечивающих достижение цели исследования.

7. Разработка «системы целей» («дерева целей») посредством определения генеральной цели функционирования системы охраны с последующей ее декомпозицией на совокупность подцелей более низких уровней иерархии.

8. Каждая выделенная цель «системы целей» достигается в процессе реализации определенных функций, что, в свою очередь, предполагает наличие соответствующих сил и средств, способных выполнять эти функции. Поэтому следующим элементом научной организации является обоснование требуемого набора функций системы и перечня необходимого для их реализации сил и средств, объединенных по целевому признаку в функциональные подсистемы. Решение данных задач осуществляется в процессе последовательной разработки и оценки структурно-функциональной модели создаваемой системы охраны.

9. Определение метода, форм и способов построения системы охраны. Разработка принципиальной модели ее построения. При необходимости могут проводиться и другие мероприятия.

Аналитический этап (всесторонняя оценка обстановки и формулирование выводов, обеспечивающих основу решения).

Этап предполагает проведение следующих мероприятий.

- Прогнозирование (оценка) угрозы диверсионно-террористического воздействия на объект охраны. Представление полученных количественнокачественных результатов оценки в удобной для восприятия табличнографической форме.

Оценка состава, состояния, обеспеченности, обученности, возможностей и способов применения сил и средств, способных выполнять функции охраны объекта на различных этапах эскалации угрозы воздействия. Подготовка необходимых информационно-аналитических данных для оценки соотношения сил и средств противоборствующих сторон (по этапам развития обстановки, направлениям, задачам, рубежам и способам действий).

- Оценка условий расположения и защиты объекта охраны. Разработка и оценки структурно-графической модели объекта охраны.

- Разработка и оценка графических моделей вариантов воздействия диверсионно-террористических (бандитских) формирований на объект охраны. Составление «контуров поражения объекта» и определение адекватных мер противодействия и защиты (зон, районов, направлений и рубежей сосредоточения основных разведывательно-поисковых, охранных и прочих усилий). 
- Разработка целесообразных вариантов состава, построения и способов действий исследуемых сил и средств.

Проектно-экономический этап (разработка решения по созданию системы).

Принятие решения заключается в научно обоснованном выборе одной из возможных альтернатив. Поэтому содержанием этапа является оценка эффективности функционирования различных целесообразных вариантов состава, построения и способов применения сил и средств и выбор по результатам оценки рационального варианта, обеспечивающего при уровне эффективности системы не ниже требуемой минимальные издержки (потери) задействованных ресурсов. Результатом мероприятий, проводимых на данном этапе, является выбор рационального варианта организационной (организационно-штатной) структуры, построения и способов применения системы охраны объекта.

В ходе этапа проводятся следующие основные мероприятия.

1. Оценка эффективности целесообразных вариантов системы охраны в условиях реализации угрозы воздействия на объект диверсионнотеррористических (бандитских) формирований на базе ранее разработанных структурно-логических и математических (аналитических и имитационных) моделей.

2. Ранжирование исследуемых вариантов по выбранным критериям эффективности и выбор наиболее предпочтительных, обеспечивающих наибольший уровень служебно-боевой эффективности в заданном диапазоне условий обстановки.

3. Оценка экономической эффективности и выбор рационального варианта, обеспечивающего наименьшие затраты людских, материальных, финансовых и прочих ресурсов.

4. При необходимости изменение условий функционирования системы (изменение обстановки) и проверка эффективности системы в более широком диапазоне условий. Выявление «уязвимых мест» системы и рисков, связанных с ними.

5. Принятие решения (при необходимости) по усовершенствованию системы и устранению «уязвимых мест».

6. Повторная оценка эффективности и проверка полученных результатов на их соответствие первоначально разработанной системе требований и целей охраны объекта. Цикл повторного проектирования и анализа продолжается до тех пор, пока результаты анализа не будут указывать на полное соответствие системы охраны целям и задачам защиты объекта.

7. Окончательное принятие решения по созданию системы охраны, его согласование, доведение до всех заинтересованных сторон и документальное оформление в соответствии с существующими требованиями.

На этом собственно научная организация системы охраны объекта заканчивается, и далее проводится практическая организация, заключающаяся в организации взаимодействия, управления, всестороннего обеспечения и решении других практических задач. 
Как видно из представленного выше материала, важнейшей частью мероприятий по обоснованию эффективной системы охраны является анализ ее эффективности в широком диапазоне условий функционирования.

Непосредственно процесс анализа эффективной системы охраны включает: определение целей системы и методов их достижения; определение характеристик проекта системы; оценку эффективности выполнения функций системы и ее общей эффективности; проектирование усовершенствований системы, обеспечивающих повышение уровня эффективности и устранение вскрытых недостатков («уязвимых мест»). Содержание и последовательность анализа эффективности системы охраны можно представить в виде определенной блоксхемы, представленной на рисунке 2. 


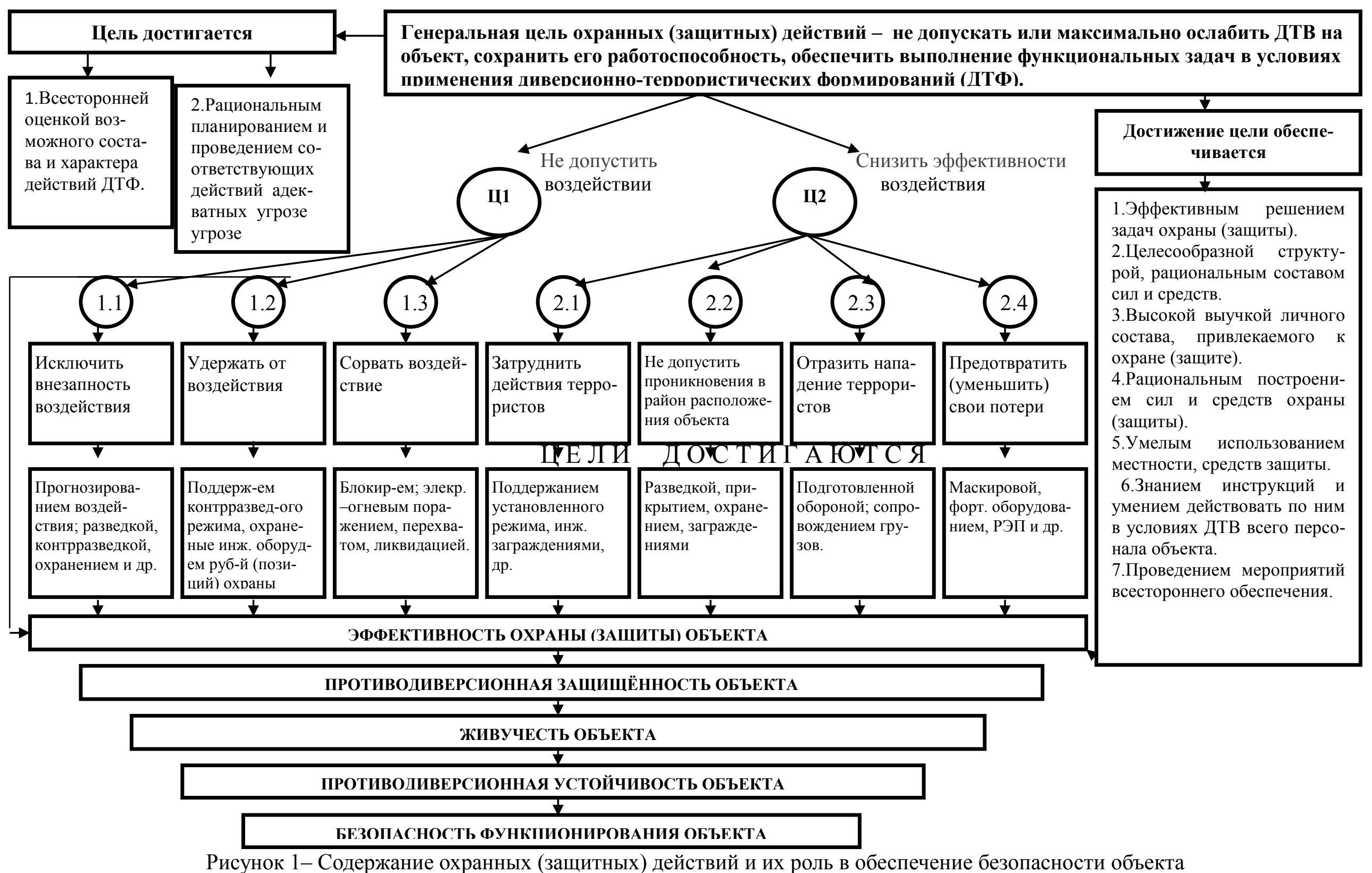




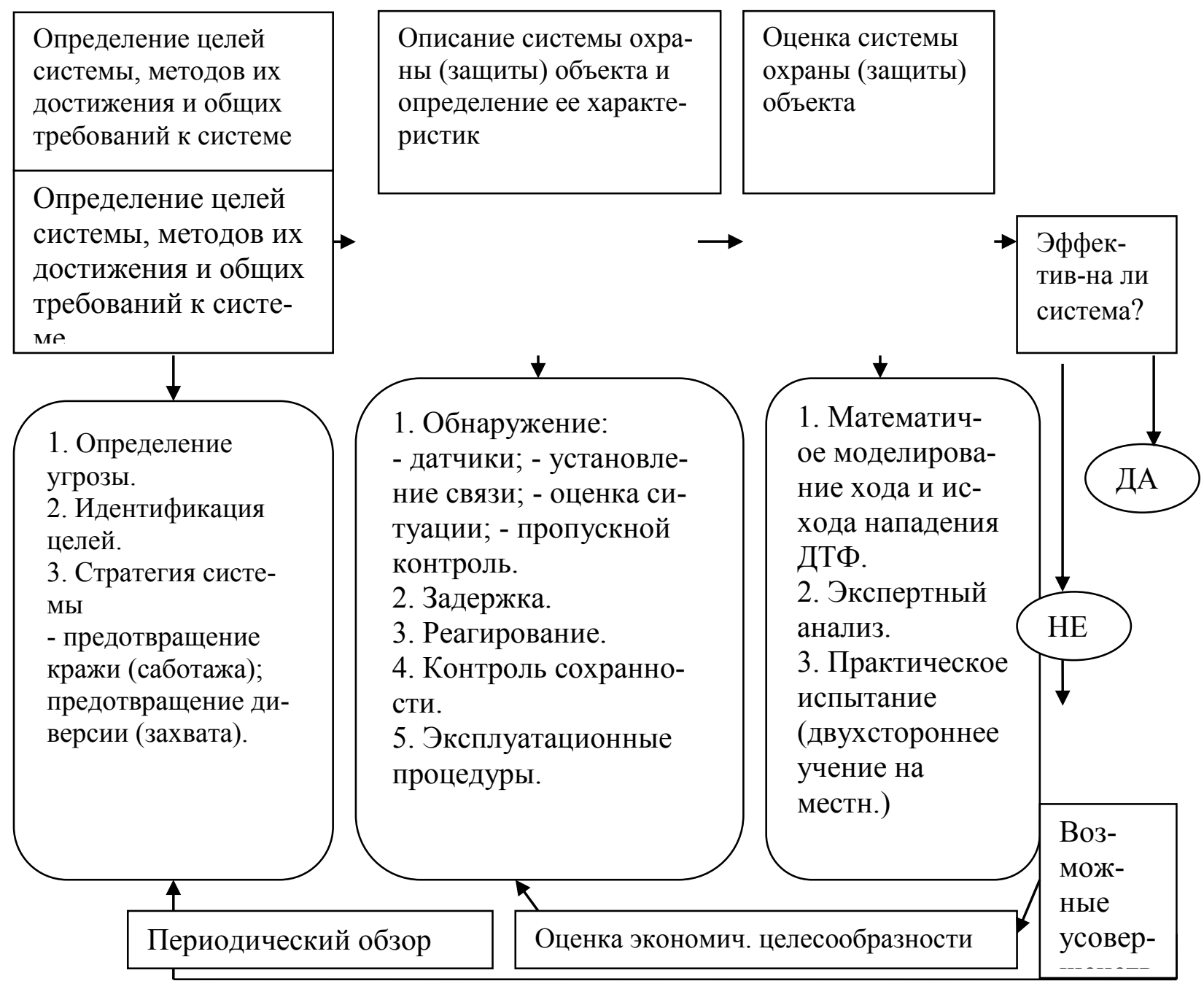

Рисунок 2 - Структурно-логическая схема содержания и последовательности процесса «анализа эффективности системы охраны объекта»

1. В результате ранее проведенного исследования решена проблемная задача, заключающаяся в разрешении противоречий между практикой, остро нуждающейся в научных рекомендациях по обеспечению безопасности объектов в условиях угрозы диверсионно-террористического воздействия противника и теорией, не имеющей достаточной научной базы для такого обеспечения.

В современных условиях решение данной проблемы имеет особую важность, которая обусловлена резким возрастанием угрозы ДТВ на экономические объекты и связанной с этим потребностью органов управления в штабных методиках, обеспечивающих обоснование решений на защиту территорий и объектов, адекватную степени угрозы.

Главная идея, положенная в основу решения проблемы защиты территорий и объектив от ДТВ, заключается в централизованном объединении усилий различных силовых структур государства и интегрировании выделяемых ими сил и средств в единую систему противодиверсионной защиты (ПДЗ) определенных зон (районов, рубежей) и объектов. Такая система призвана обеспечить в зоне ответственности эффективную нейтрализацию диверсионно- 
террористических формирований (ДТФ) и безопасность функционирования всех расположенных в зоне объектов на основе централизации управления и рационализации состава, структуры, построения и способов применения сил и средств ПДЗ. Реализация этой идеи на практике означает возможность обеспечить одновременно как зональную (в общей системе ПДЗ), так и непосредственную защищенность объектов и группировок.

Зональная защищенность обеспечивается за счет создания в определенных зонах защиты, в границах которых расположены соответствующие экономические объекты, определенных группировок сил и средств ПДЗ. Основу их составляют боеготовые формирования ФСБ, МВД, МО и других силовых структур государства, имеющих соответствующую правовую базу, вооружение и специальную подготовку. Эти силы в состоянии обеспечить установление и поддержание в зоне своей ответственности определенного режима, вести активные разведывательно-поисковые, режимно-предупредительные, охранные и др. специальные действия, направленные на выявление и своевременное обезвреживание диверсантов и террористов, а также поддерживать общий порядок в зоне (районе, полосе) ответственности.

Непосредственная защищенность экономических объектов обеспечивается созданием рациональных по составу, построению (эшелонированию) и способам применения имеющихся сил и средств систем их охраны. Основу таких систем составляют штатные и - в угрожаемый период или во время войны - специально выделяемых (привлекаемых) формирования различных силовых структур государства.

Реализация всех предложенных мероприятий (действий) ПДЗ, как показывают результаты математического моделирования, позволит обеспечить требуемые уровни противодиверсионной защищенности и живучести объектов и тем самым обеспечить безопасность их функционирования в условиях угрозы диверсионно-террористического воздействия.

2. Непосредственно процесс проектирования эффективной системы охраны объекта может включать последовательное решение нескольких взаимосвязанных задач. Их содержание и последовательность решения представлены следующим алгоритмом (вариант):

1 - всесторонняя оценка обстановки. Сущность проводимых мероприятий заключается в сборе, обработке, обобщении и анализе исходных данных о составе, состоянии и возможностях диверсионно-террористических формирований, силах и средствах, привлекаемых к охране (защите) объекта, условиях расположения, составе и возможностях персонала и технического оснащения объекта;

2 - оценивание гипотетического состояния противодиверсионной защищённости объекта (то есть возможности противодействия системы охраны без учета рационального состава, времени нападения и способа действий террористов); 
3 - оценивание уровня диверсионно-террористической угрозы (в том числе и прогнозирование рационального состава, времени нападения и способов действий террористов, результатов и последствий их воздействия на объект);

4 - оценивание уровня живучести (устойчивости) объекта при условии реализации угрозы ДТВ (проводится при необходимости);

5 - комплексный анализ результатов (данных), полученных в ходе решения предыдущих задач, и выработка предварительного решения по повышению эффективности проводимых охранных мероприятий (структуре, построению и способам применения сил и средств системы охраны);

6 - повторное моделирования обстановки (хода и исхода нападения на объект) с учетом проведения дополнительных охранных (защитных) мероприятий и анализ результатов моделирования (данный цикл повторяется до получения удовлетворительных результатов, обеспечивающих надежность охраны объекта);

7 - принятие итогового решения по обеспечению безопасности объекта (составу, построению и способам применения сил и средств системы охраны), удовлетворяющего всем нормам и требованиям.

Результатом проектирования становится всесторонне обоснованный вариант структуры, состава, построения (эшелонирования) и способов применения сил и средств системы охраны объекта, адекватных уровню диверсионнотеррористической угрозы.

3. Для реализации разработанного методологического подхода, отраженного в алгоритме, разработана соответствующая система методов, моделей и методик их применения, составляющая основу научно-методического аппарата исследования.

Теоретическая и практическая значимость полученных результатов. Разработанный научно-методический аппарат позволяет установить закономерности и оценить ожидаемую эффективность процессов, мероприятий и действий, направленных на защиту объектов от диверсантов и террористов, и на этой основе получить научно обоснованные рекомендации по обеспечению их живучести, противодиверсионной устойчивости и в целом безопасности функционирования в условиях прогнозируемого диверсионно-террористического воздействия.

Достоверность полученных результатов обеспечивается применением современных методов исследования и ЭВТ; математическим аппаратом, апробированным в оперативно-тактических (оперативно-тыловых) расчетах; утвержденной нормативно-справочной (исходной) информации.

\section{ВЫВОДЫ}

Математические основы разработанного научно-методического аппарата главным источником своего развития имеют достижения, полученные в классических теориях: теории вероятностей, теории исследования операций, теории системного анализа, теории организации, теории поиска и в других известных теориях, чем подтверждается достоверность полученных результатов. 
Разработанные методы, модели и методики опробованы на большой статистике практических расчетов и в целом доказали свою адекватность и научную объективность оценок.

Результаты исследования представляют собой относительно новый взгляд на решение проблемы защиты территорий и объектов от ДТВ. Они в целом соответствуют современным условиям и могут быть использованы для углубленного изучения заинтересованными лицами процессов обеспечения и повышения противодиверсионной защищенности, живучести и безопасности функционирования важных экономических объектов в условиях угрозы диверсионнотеррористического воздействия. \begin{tabular}{ccl} 
Михайлов, А.Г. & \multicolumn{1}{c}{ ЛИТЕРАТУРА } \\
1. Методы & обоснования системы \\
противодиверсионной защиты тыла объединения (тылового объекта) / А.Г.
\end{tabular} Михайлов - СПБ.: ВАТТ, 2005. - 240 с.

2. Абчук, В.В. Справочник по исследованию операций/ В.В. Абчук [и др.] - М.: Воениздат, 1979. - 368 с.

3. Сурин, Д.В. Аналитические методы оценки защищенности и живучести объектов и комплексов/ Д.В. Сурин - МО РФ, 1996. - 145с.

4. Военный энциклопедический словарь. - М.: Воениздат, 1983. $864 c$.

5. Основы математического моделирования /Учебное пособие. - СПб.: BATT, 1996. - 308c.

6. Вентцель, Е.С. Исследование операций. Задачи, принципы, методология/ Е.С. Вентцель - М.: Наука, 1988. - 208c.

7. Мильнер, Б.З. Теория организации / Б.З. Мильнер - М.:ИНФРА M, 2007. - 797 c. 